\title{
Moda e Sustentabilidade: proposta de sistema produto-serviço para Setor de Vestuário
}

\author{
Fashion and Sustainability: Proposal of product-service system for Apparel Industry
}

\author{
MARTINS, Suzana Barreto; Doutora; Universidade Estadual de Londrina \\ suzanabarreto@onda.com.br
}

SAMPAIO, Cláudio Pereira de; Mestre; Universidade Estadual de Londrina qddesign@hotmail.com

MELLO, Nathalia Castilho; Graduada; Universidade Estadual de Londrina nacmello@gmail.com

\begin{abstract}
Resumo
Este artigo apresenta o resultado de uma proposta conceitual de sistema produto-serviço (PSS), para o Setor de Vestuário, abrangendo as dimensões econômicas, ambientais e sociais. Dentre as questões ambientais, estão a minimização do desperdício de materiais e impactos ambientais decorrentes do processo produtivo e o reaproveitamento de matéria prima já utilizada e comercializada. Em relação aos aspectos econômicos, considerou-se a redução de gastos financeiros com recursos, e a criação de diferencial competitivo por meio de propostas de PSS. Já na dimensão social, o foco foi promover a mudança de comportamento propondo um novo cenário de consumo para o Setor. O método de pesquisa adotado foi o estudo de caso, realizado junto a uma empresa do Setor de Vestuário, localizada em Londrina, no Paraná. Após a coleta e avaliação de dados qualitativos e quantitativos sobre o Setor e a empresa estudada, foram propostos novos cenários que prevêem a concepção de uma nova coleção de produtos de moda, reutilizando a matéria-prima de produtos que já foram comercializados anteriormente, assim como novos usos e hábitos de consumo para produtos de moda.
\end{abstract}

Palavras-Chave: Sustentabilidade; Sistema produto-serviço; Design. Vestuário; Moda.

\begin{abstract}
This article presents a conceptual proposal of a product-service system (PSS) for the clothing sector, encompassing the economic, environmental and social dimensions. Among environmental issues, are the minimization of waste materials and environmental impacts of the production process and the reuse of raw materials previously used and commercialized. Regarding the economic aspects were considered the reduction of financial expenditures with resources, and the creation of competitive advantage through PSS proposals. In the social dimension, the focus was to promote behavior change by proposing a new scenario of consumption for the Sector. The research method was the case study, carried out in a clothing company, located in the city of Londrina, in Paraná state, Brazil. After collecting and evaluating qualitative and quantitative data about the sector and the studied company, it was proposed new scenarios that foresee the conception of a new collection of fashion products, by reusing the raw material of products that had already been commercialized, as well as new habits and consumption patterns for fashion products.
\end{abstract}

Keywords: Sustainability; Product-service system; Design; Clothing; Fashion. 
Moda e Sustentabilidade: proposta de sistema produto-serviço para Setor de Vestuário

\section{Introdução}

Os danos ambientais causados pelo 'design convencional' e pela indústria, pelo fato de não serem considerados os impactos ambientais decorrentes das atuais atividades industriais produtivas, exigem um repensar urgente dos métodos de produção e consumo para garantir um meio ambiente propício às futuras gerações. Para alcançar a sustentabilidade é necessária, segundo Vezzoli e Manzini (2008), uma nova maneira de conceber produtos e serviços: o design sustentável é o ato de produzir produtos, serviços e sistemas com um baixo impacto ambiental e uma alta qualidade social, além de viáveis economicamente.

O Setor de Vestuário e confecções apresenta, neste contexto, grandes desafios à sustentabilidade, pois apresenta uma série de impactos ao meio ambiente que vão desde o grande consumo de matéria-prima e energia ao longo da pré-produção, produção, distribuição e consumo dos produtos, até a geração de resíduos e emissões no fim de vida dos mesmos. Mas este setor apresenta também, para o design, um campo bastante fértil de pesquisa e desenvolvimento com vistas à sustentabilidade, pois ainda há muito a ser feito nesta área de estudo, especialmente quanto às empresas brasileiras, sendo uma delas objeto de estudo neste artigo.

Neste contexto, o objetivo deste trabalho é propor um sistema produto-serviço (PSS) que engloba também visando a evitar o desperdício de materiais e reaproveitar a matéria prima já utilizada e comercializada antes que seja descartada de forma indevida, mas sem desconsiderar os aspectos econômicos, como a redução de gastos com recursos e a criação de diferencial competitivo por meio de proposta de PSS.

\section{O Contexto: Sustentabilidade e o Setor de Vestuário e Confecção}

\section{Aspectos sócio-econômicos}

As regiões sudoeste e norte do Paraná têm expressiva produção no setor do vestuário e confeç̧ão contribuindo na geração de emprego e renda tanto no cenário local como no cenário nacional. Devido ao grande volume de produção e a expansão do setor, fez-se necessário agrupar micro, pequenas, médias e grandes empresas produtoras em Arranjos Produtivos, denominados Arranjos Produtivos Locais - APL.

O Arranjo Produtivo Local - APL é o termo que se usa para definir uma aglomeração de empresas com a mesma especialização produtiva e que se localiza em um mesmo espaço geográfico. Os APLs mantêm vínculos de articulação, interação, cooperação e aprendizagem entre si, contando também com apoio de instituições locais como Governo, associações empresariais, instituições de crédito, ensino e pesquisa.

Em toda a região do APL indicado são mais de 400 micro, pequenas, médias e grandes empresas instaladas que produzem em torno de 1.1 milhão/peças/mês, sendo o segundo setor que mais gera emprego (IPARDES, 2006) e primeiro setor, segundo o IBGE.

\section{Arranjo Produtivo Local da Moda Masculina do Sudoeste do Paraná}

O Arranjo Produtivo Local da Moda Masculina do Sudoeste do Paraná tem uma área de abrangência de 42 municípios predominantemente de pequeno porte (55\% até $10 \mathrm{mil}$ hab- 
Suzana Barreto Martins; Cláudio Pereira de Sampaio; Nathalia Castilho Mello

itantes; $29 \%$ de $10 \mathrm{mil}$ a $20 \mathrm{mil} ; 12 \%$ de $20 \mathrm{mil}$ até $30 \mathrm{mil} \mathrm{e}$; $4 \%$ acima de $60 \mathrm{mil}$ ), sendo que $96 \%$ dos municípios têm menos de 50 anos de emancipação político-administrativa.

A região faz fronteira a oeste com a Argentina e ao sul com o Estado de Santa Catarina e está inserida no programa PROMESO do Ministério da Integração Nacional, através da MESOMERCOUL que é composta por 404 municípios sendo, 232 do norte do Rio Grande do Sul, 130 do Oeste de Santa Catarina e 42 do Sudoeste do Paraná. Um dos programas estruturantes da MESOMERCOSUL é o de "Implantação e Fortalecimento da Agroindústria Familiar- Geração de Emprego e Renda". Desta forma, o foco neste setor deu-se pela razão da peculiaridade entre as regiões e de que regiões Oeste de Santa Catarina e Sudoeste do Paraná possuem a melhor distribuição fundiária do Brasil (minifúndio) com aproximadamente 5으 mil propriedades rurais em cada uma das respectivas regiões onde a agroindústria familiar rural está em franca expansão.

Em toda a região do APL da Confecção Moda Sudoeste são mais de 400 micro, pequenas, médias e grandes empresas instaladas que produzem em torno de1.2milhão/peças/mês, sendo o segundo setor que mais gera emprego (INSTITUTO PARANAENSE DE DESENVOLVIMENTO ECONÔMICO E SOCIAL, 2006). Os municípios-alvo deste projeto representam, de forma comparativa com a região total do APL, o seguinte: a) $23 \%$ dos $n^{\circ}$ de municípios; b) $14,6 \%$ do território;c) 20,4\% da população; d) 20,5\% do total de empresas (todos os setores); e) $18,7 \%$ de empregos gerados (todos os setores);f) 30,5\% do total de empresas do segmento confeccionista e; f) $38,7 \%$ da produção, indicadores esses significativos para a concentração desses municípios do entorno da fronteira com Argentina.

\section{Arranjo Produtivo Local do Norte do Paraná}

Já a região norte do Paraná, conta com articulação setorizada e constituída desde 2005 com o APL de Vestuário de Londrina e Região, composto por representantes das entidades: Sebrae; Senai; UEL; Fiep; Sindicato; UTFPR; Caixa Econômica entre outros e por micro, pequenas, médias e grandes empresas do setor. Com base no planejamento estratégico, o objetivo do Setor de Vestuário é ter o APL de Vestuário de Londrina e Região, estruturado e reconhecido como referência, tanto em moda quanto em gestão de produção. A visão do Setor de Vestuário caracteriza-se pela união, articulação e representatividade política, com meta de ser reconhecido como referencial de moda com o apoio de empresas com marcas sólidas, profissionais qualificados, tecnologia de ponta e responsabilidade sócio-ambiental. No entanto, ressalta-se que nesse momento, devido a problemas de ordem estrutural, tal APL encontra-se inativo.

\section{Aspectos ambientais: impactos gerados pela produção do vestuário}

Há uma premente necessidade de desenvolverem-se novos modelos de consumo e produção para o setor de moda e vestuário. O setor tem um significativo impacto econômico, ambiental e social que justifica tal premência. Somente o uso excessivo, ou incorreto, de agrotóxicos neste setor provoca cerca de 25 milhões de pessoas intoxicadas por ano, de acordo com a organização não-governamental Environmental Justice Foundation (2007).

Na produção de algodão, por exemplo, cerca de $40 \%$ do algodão é fibra e o restante é semente transformada em óleos comestiveis e ração animal. Isso significa que numa plantação onde o uso de agrotóxicos acontece como prática convencional, boa parte dos insumos quími-

Projética Revista Científica de Design I Universidade Estadual de Londrina I V.2 I N.1 I Junho 2011 
Moda e Sustentabilidade: proposta de sistema produto-serviço para Setor de Vestuário cos permanece concentrada nas sementes que serão transformadas em óleos de cozinha e ração de animais que servem como base da nossa alimentação. O processo de obtenção em grande escala das fibras naturais no sistema convencional implica a utilização de diversas substâncias químicas, como fertilizantes, herbicidas, praguicidas, que contaminam o solo, a fauna e as pessoas que trabalham, quando utilizadas de forma irresponsável.

Por outro lado, o processo de fabricação de fibras sintéticas derivadas de hidrocarbonetos acelera o esgotamento do petróleo gerando quantidade considerável de resíduos não-biodegradáveis e difíceis para reciclar. Os processos de acabamento, tintura e estamparia também utilizam sustâncias químicas muitas vezes tóxicas, assim como o processo para curtir o couro, sem contar a diversidade de materiais heterogêneos reunidos em um calçado como couro, tecidos, elementos metálicos, plásticos, difíceis de reciclar (MCDONOUGH; BRAUNGART, 2002).

Grande parte deste e de outros impactos é ignorada ou mesmo desconhecida pelos profissionais que atuam no desenvolvimento de soluções para produtos de moda e vestuário. De fato, segundo Viñolas Marlet (2005, p. 338), “[...] deve-se também à ênfase dos aspectos psicológicos por meio da imagem pessoal, a dependência das marcas e o desconhecimento de que por trás de um simples produto de moda coexistem impactos sociais e ambientais". O sistema moda impõe um ritmo de obsolescência programada muito rápido em que os produtos de moda são descartados muito antes do final da sua vida potencial, o que é diametralmente contrário aos axiomas do design sustentável.

A deficiente gestão dos resíduos no Setor de Vestuário e de confecção tem ocasionado modificações nas características do solo, da água e do ar, podendo poluir ou contaminar o meio ambiente, que ocorre quando esses resíduos modificam o aspecto estético, a composição ou a forma do meio físico. O meio é considerado contaminado quando existe a mínima ameaça à saúde dos homens, plantas ou animais. A grande diversidade da atividade produtiva gera diferentes resíduos e impactos ambientais, sendo que o setor do vestuário e confeccionista do estado do Paraná não geram resíduos sólidos de grande poder impactante, porém, de elevadíssimo volume, e diferentes tipos de resíduos. A toxidade dos mesmos não é significativa, porém, o volume elevado afeta outras variáveis ambientais, como as emissões de CO2 e a exaustão de recursos naturais não renováveis.

\section{Aspectos ambientais em nível regional}

Em agosto de 2005 o Ministério Público Estadual, prefeitos da região de Londrina e o Instituto Ambiental do Paraná - IAP realizaram encontro na cidade de Dois Vizinhos, Paraná, para discutirem a problemática da coleta e destinação dos resíduos industriais dos municípios que até então eram coletados pelos municípios e enviados aos chamados "lixões". A partir de novembro do mesmo ano, as municipalidades interromperam os serviços de coleta e destinação dos resíduos sólidos, ficando a cargo das empresas essa atividade. Isso demonstra a preocupação regional com a questão de minimização de resíduos têxteis e impactos ambientais, seja por parte dos empresários como do setor público.

A maioria das empresas do setor do vestuário adota como prática a doação de sobras de tecidos para entidades filantrópicas como APAE's, Secretarias de Ação Social, escolas e outras afins. Em contrapartida, o volume das doações aumentou acima da capacidade destas entidades em absorver o volume de resíduos gerados pelo setor do vestuário. Como medida paliativa, resíduos têxteis passaram a ser comercializados ou doados para empresas de outras 
Suzana Barreto Martins; Cláudio Pereira de Sampaio; Nathalia Castilho Mello

regiões. Porém, da mesma forma como ocorreu na doação, tais empresas pararam de realizar a coleta, seja para compra ou doação, porque houve excesso de oferta de resíduos no mercado.

Neste contexto, é premente o desenvolvimento de soluções que contemplem todo o ciclo de vida dos produtos do setor do vestuário. No presente artigo, o foco é justamente a concepção dos produtos do setor considerando o ciclo de vida e, também, os subprodutos passíveis de produção a partir dos resíduos do processo de manufatura. Com tal ênfase, cria-se a oportunidade não somente de reduzir custos, mas também de aumentar a competitividade das indústrias por meio da diferenciação em relação aos concorrentes nacionais e internacionais. A dimensão ambiental representa, nesse caso, um dos aspectos de competitividade que tem atraído de forma crescente a atenção do público consumidor.

\section{O objeto de estudo: Lucca Sportswear}

Lucca Sportswear é uma empresa localizada na cidade de Londrina - PR, que desde 1996 atende clientes de classe média alta e alta com seus produtos do segmento casual. A empresa iniciou com a venda de produtos para alunos de academias de ginástica e logo transformou-se em uma empresa de renome na região e no cenário nacional. 0 crescimento não planejado acarretou uma série de desperdícios de tecidos e aviamentos ao longo dos anos.

\section{Abordagens de solução: 0 design para a sustentabilidade}

Manzini e Vezzoli (2002) apresentam pelo menos quatro abordagens possíveis em design para a sustentabilidade (Figura 1), com foco especificamente na redução de impactos ambientais causados pelos produtos, ou considerando o sistema como um todo. No primeiro caso (foco em produtos), pode-se atuar a partir do redesign ou do design de novos produtos intrinsicamente sustentáveis. No caso de uma abordagem sistêmica, pode-se repensar todo o sistema de produção e consumo à volta deste, ou seja, todo o ciclo de vida, que envolve também uma série de operações complementares, serviços e outros elementos. Neste caso, é possível propor serviços que busquem desmaterializar o consumo, bem como criar novas propostas de cenários de estilos de vida mais sustentáveis.

Os novos produtos-serviços podem tornar-se intrinsecamente sustentáveis caso consigam superar a inércia cultural/comportamental dos consumidores, mas devem ser considerados pelas empresas que os fornecem de forma estratégica em seus negócios. Manzini e Vezzoli (2002) apontam que é somente a partir desta possibilidade que pode haver soluções realmente coerentes com a perspectiva de sustentabilidade e, portanto, um "design sustentável".

A proposição de novos cenários sustentáveis, por sua vez, implica na promoção de novos critérios de qualidade no plano cultural, e visa a modificar o modo como são buscados os resultados tanto por parte das empresas dos consumidores. Neste caso, o papel do designer é importante, mas há dependência de outras esferas de decisão, sejam elas políticas, empresariais ou mesmo da sociedade organizada (MANZINI; VEZZOLI, 2002).

A abordagem utilizada neste trabalho parte da hipótese de que os sistemas produto-serviço, pelo seu caráter sistêmico, podem apresentar resultados mais eficazes, em termos de sustentabilidade. Utiliza-se também a criação de novos cenários como uma ferramenta particu-

Projética Revista Científica de Design I Universidade Estadual de Londrina I V.2 I N.1 I Junho 2011 
Moda e Sustentabilidade: proposta de sistema produto-serviço para Setor de Vestuário larmente útil para a visualização das novas possibilidades de produção e consumo propostas.

Neste caso, as propostas de novos produtos apresentadas ao final deste artigo resultam dos novos cenários propostos, fugindo, portanto, da abordagem tradicional do design em geral e, mais especificamente do design de moda. Tradicionalmente os designers são formados para desenvolver novos produtos, e não novos sistemas de produção e consumo.

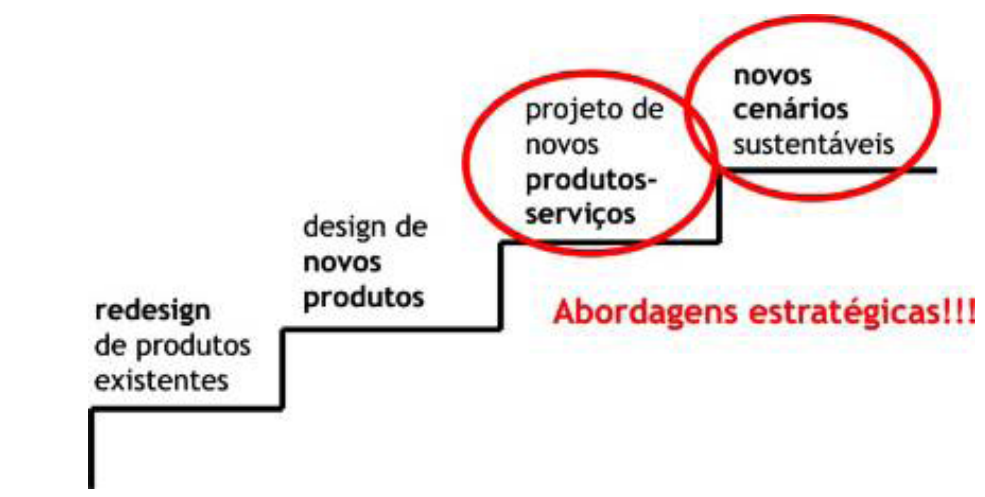

Figura 1 - Os quatro níveis de atuação do design para a sustentabilidade

Fonte: Elaborado com base em Manzini e Vezzoli (2002)

Deste modo, a pesquisa visando à inovação na proposta descrita neste artigo busca conferir diferenciação às empresas do Setor de Vestuário estudado, por meio de produtos e processos com maior eficiência no consumo de matéria-prima e energia, bem como facilitar a reciclagem e reuso de seus componentes. Além da sensibilização do consumidor quanto a critérios de escolha de produtos mais sustentáveis, foram realizados também estudos piloto, buscando investigar possibilidades de promoção de mudanças reais nos estilos de vida e consumo. Isto implicará na concepção de novos produtos e serviços para o setor que substituam os atuais, ou o projeto de novos produtos-serviços intrinsecamente sustentáveis.

Finalmente, com o objetivo de prover informações para alimentar o processo de planejamento estratégico nas empresas, o projeto contemplou a proposição de cenários de longo prazo que correspondam ao estilo de vida sustentável no Setor de Vestuário. A proposição de novos cenários sustentáveis, por sua vez, implica na promoção de novos critérios de qualidade no plano cultural, buscando modificar o modo como são buscados os resultados, tanto por parte das empresas como dos consumidores. Portanto, pretende-se inserir inovações tanto no produto como também no processo de produção no Setor de Vestuário.

É importante ressaltar que, tanto no que se refere aos desafios de sustentabilidade na produção e consumo de produtos de moda quanto à proposição de estratégias de ação com a finalidade de reduzir impactos e inserir a sustentabilidade no setor de vestuário, já foram objeto de extensa pesquisa, entre elas as conduzidas por Martins e Santos (2008) Martins et al. (2011), Martins e Vascouto (2007), Martins e Castro (2007), Madsen et al. (2007) e Bruce, Daly e Towers (2004). Desta forma, o objetivo deste trabalho é apresentar os resultados de um projeto prático que considera tanto os desafios quanto as estratégias citadas acima.

\section{A abordagem de sistemas produto-serviço}

Sistemas Produto-Serviço (Product Service Systems, ou PSS) têm como premissa básica a desmaterialização do consumo, buscando a substituição do benefício pela posse de produtos para o benefício pelo acesso aos benefícios finais esperados. Segundo UNEP (2002 apud 
Suzana Barreto Martins; Cláudio Pereira de Sampaio; Nathalia Castilho Mello

MANZINI; VEZZOLI, 2004), PSS podem ser definidos como "o resultado de uma inovação estratégica, com mudança no foco dos negócios do planejamento e venda de produtos físicos tão somente, para a comercialização de sistemas de produtos e serviços que, em conjunto, que são capazes de atender a demandas específicas dos clientes". Brezet et al (2001) ressalta ainda a dimensão ambiental dos PSS, afirmando que "serviços ecoeficientes são sistemas de produtos e serviços que são desenvolvidos para causar um mínimo impacto ambiental com o máximo de valor agregado".

Além da abordagem de PSS, este artigo propõe que, ao se desenvolver os produtos dentro destas novas propostas de sistema, seja utilizado o conceito de life cycle design, ou design do ciclo de vida. Segundo Vezzoli e Manzini (2008), "o objetivo ambiental do life cycle design é o de reduzir os inputs de materiais e energia, assim como o impacto de todas as emissões e dejetos". O designer planeja o futuro do produto para reduzir o impacto ambiental em todo o seu ciclo de vida: desde a seleção da matéria-prima, fabricação, distribuição, uso e descarte.

O foco no produto, também chamado de ecodesign, implica em selecionar materiais de baixo impacto ambiental, aperfeiçoar técnicas de produção, reduzir impactos ambientais dos produtos, otimizar o tempo de vida e o processo no final do ciclo de vida útil, conforme Breezet (apud MARTINS; SAMPAIO, 2006). No caso de PSS aplicado ao setor de vestuário, diversos estudos já foram conduzidos anteriormente de forma exploratória, dentre eles os de Vezzoli (2000), e Vezzoli e Ceschin (2008).

\section{RESULTADOS}

\section{Um novo cenário local: Eco Lucca}

Esta proposta implica na recuperação do produto antes que este chegue ao seu destino final: o meio ambiente. Trata de recuperar a sua funcionalidade e agregar um novo valor conceitual de produtos para a marca Lucca. Além de inserir as questões ambientais em uma empresa de pequeno porte, foram consideradas também questões econômicas relevantes, como evitar o desperdício de materiais, reduzir os investimentos em novos materiais e ocupar a produção em tempos de baixa atividade. Aumentar o ciclo de vida, neste contexto de uma empresa de pequeno porte é, talvez, o primeiro passo para uma mudança no quadro do desperdício produzido pelas empresas confeccionistas locais.

Com base nestas questões, o projeto de uma nova linha, denominada Eco Lucca, determina a concepção de novos produtos focados para o mesmo público já atendido, e projetados com a mesma qualidade, reutilizando a matéria prima. Com isso, prevê-se o reuso dos produtos que já foram comercializados, seguindo de maneira sistêmica seis etapas:

1) Sistema de recolhimento

2) Avaliação das condições das peças

3) Estudo de modelagem/ Desconstrução

4) Banco tecidos e de aviamentos

5) Estudo de viabilidade/ re-design

6) Re-modelagem/ produção

7) Marketing. 
Moda e Sustentabilidade: proposta de sistema produto-serviço para Setor de Vestuário

Relação produto-sistema-serviço:

O sistema proposto pode ser descrito de forma simplificada utilizando-se o esquema representado na Figura 2.

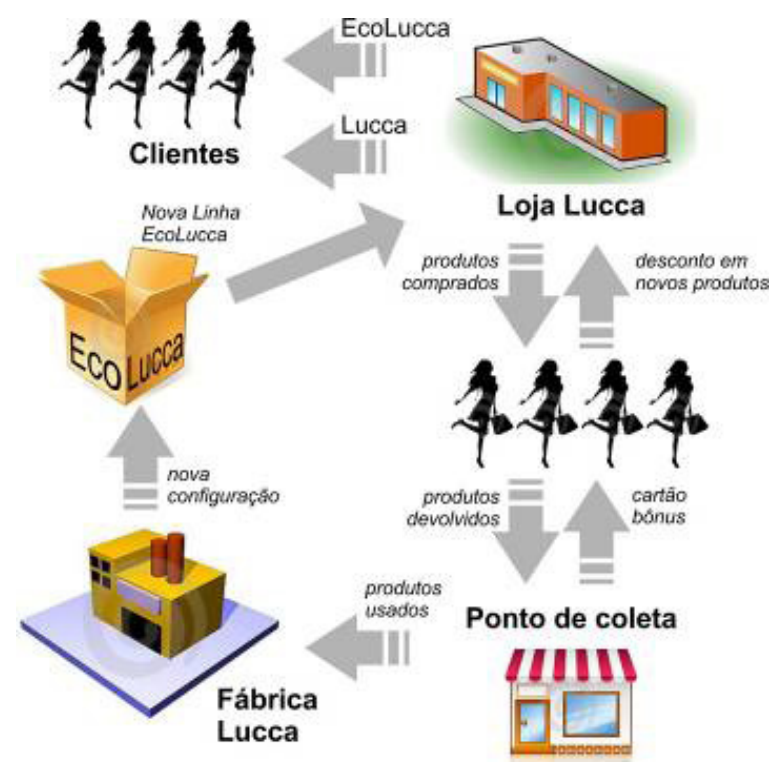

Figura 2 - Esquema visual do sistema Eco Lucca Fonte: Elaborado pelos autores

\section{Relação produto/produção:}

Além de prever o funcionamento do sistema como serviço, é proposta uma nova abordagem produtiva (Figura 3), fundamentada principalmente no recolhimento das peças das duas últimas coleções utilizadas pelo cliente da empresa Lucca e sua separação e quantificação no sistema de produção. As etapas seguintes são descritas em detalhes nos itens 4.5 a 4.9.

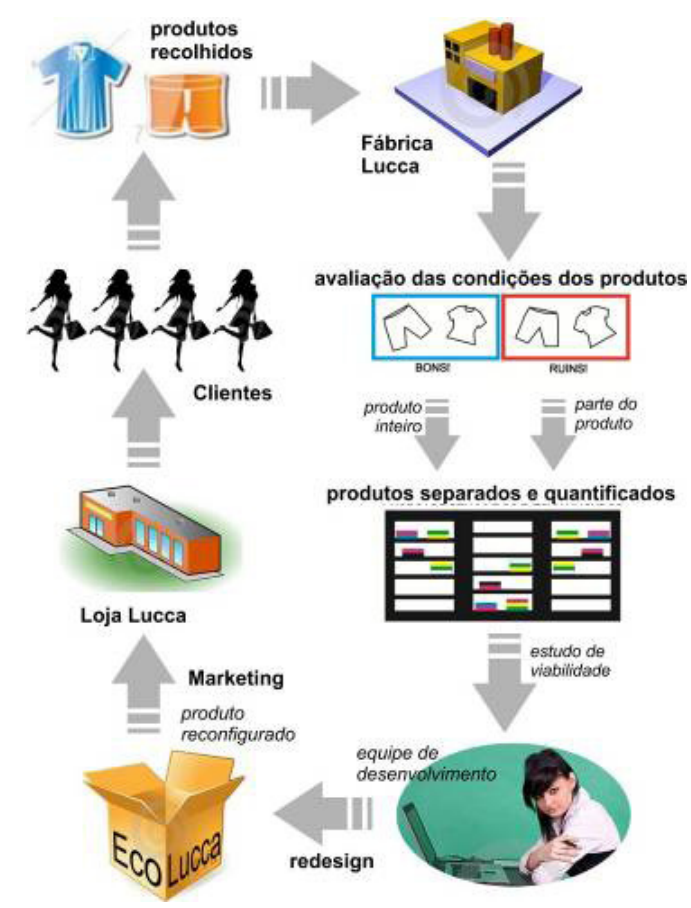

Figura 3 - Relação produto-produção no sistema Eco Lucca Fonte: Elaborado pelos autores 
Suzana Barreto Martins; Cláudio Pereira de Sampaio; Nathalia Castilho Mello

\section{Sistema de Recolhimento:}

A empresa Lucca Sportwear atende Londrina e outras cidades do Brasil. Porém, é na cidade de Londrina que a marca já tem uma imagem consolidada e um público fiel. Para que a peça seja devolvida à loja, as clientes obterão um cartão bônus para cada peça entregue, o que significará um desconto de $05 \%$ a $20 \%$ sobre uma nova compra, seguindo o esquema (Quadro 1):

\begin{tabular}{|c|c|}
\hline Devoluções & Descontos sobre novas peças \\
\hline 1 peça & $10 \%$ \\
\hline 2 peças & $15 \%$ \\
\hline 3 peças & $20 \%$ \\
\hline
\end{tabular}

Quadro 1 - Relação entre peças devolvidas e descontos obtidos pelo consumidor no sistema Eco Lucca Fonte: Elaborado pelos autores

\section{Avaliação das condições dos materiais:}

Após todo o material ser recolhido e separado inicia-se um processo de avaliação da qualidade destes materiais. Nesta etapa verifica-se se o material ainda está em boa qualidade de uso, se é possível reutilizá-lo em um todo, ou em partes. Por fim, faz-se uma avaliação da qualidade em que se encontra a matéria-prima e o que é possível fazer para recuperá-la.

\section{Estudo de modelagem/ desconstrução:}

O modelista recolhe as bases de modelagens e as fichas técnicas das peças recolhidas, desconstrói e estuda uma peça de cada modelo e envia os dados para o setor de criação.

\section{Banco de Tecidos e Aviamentos:}

O restante das peças é desconstruído, reservado e quantificado, para que o responsável pelo PCP (planejamento e controle de produção), possa numerar posteriormente a quantidade de peças de cada modelo que será confeccionada.

\section{Re-design/ Estudo de viabilidade:}

Nessa etapa, o designer de moda, juntamente com a equipe de desenvolvimento de produto, analisa as novas possibilidades de construção e interferências, conferindo um diferente aspecto e uma nova referência à coleção. Aqui, para cada peça recolhida, surgirão pelo menos três peças novas como opção de escolha. Depois de geradas as alternativas, reúnem-se modelista e designer para fazer a análise da viabilidade de produção das peças. Os critérios de escolha são: maior economia de material, maior aproveitamento de aviamentos, menor inserção de interferências (bordados, e estampa localizada/silk) e menor tempo para produção. Nas Figuras 4 a 9 são apresentados exemplos de estudos de novas propostas, utilizando-se o método de desconstrução-classificação-reconstrução descrito anteriormente. 


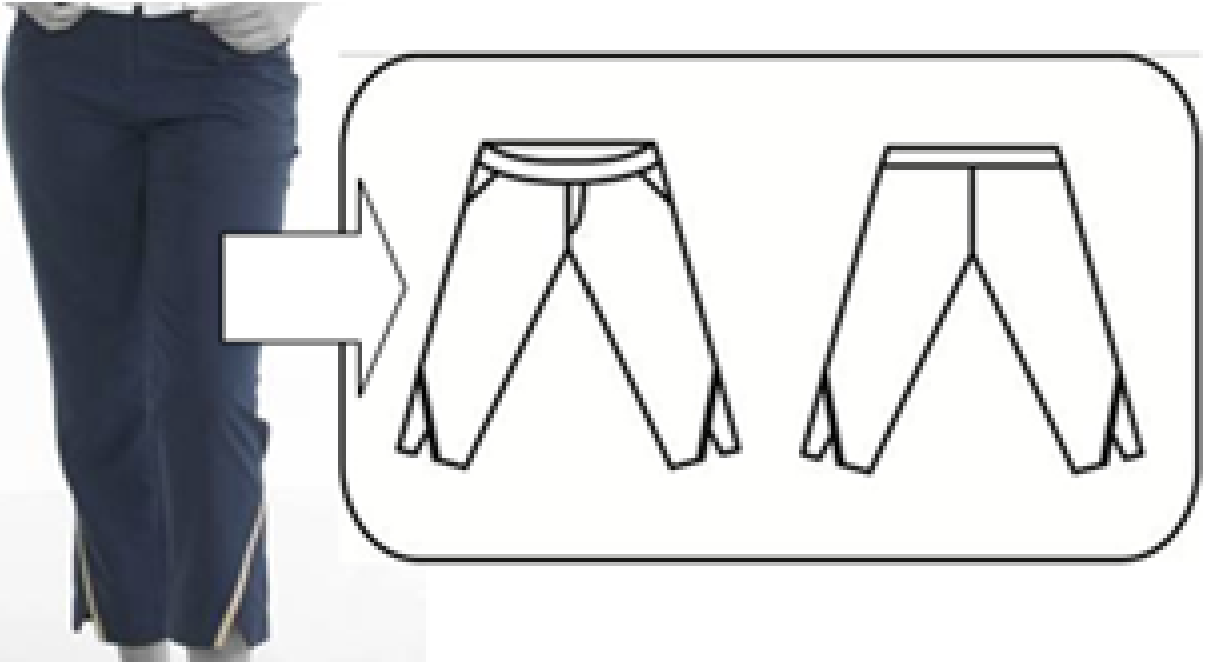

Figura 4 - Exemplo de aplicação (desenho técnico da peça existente)

Fonte: Elaborado pelos autores

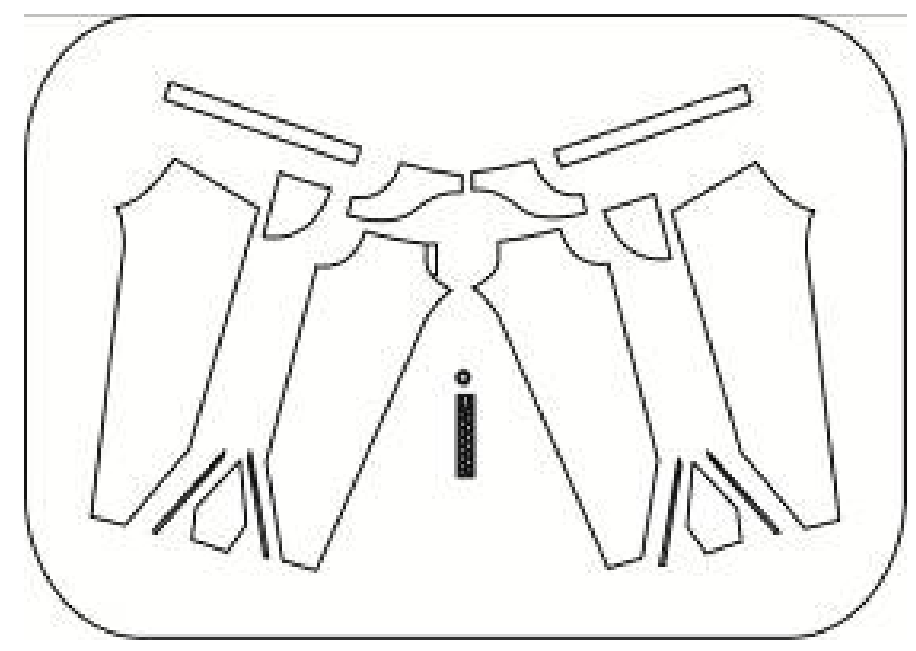

Figura 5 - Estudo das partes que compõem a peça existente (classificação) Fonte: Elaborado pelos autores

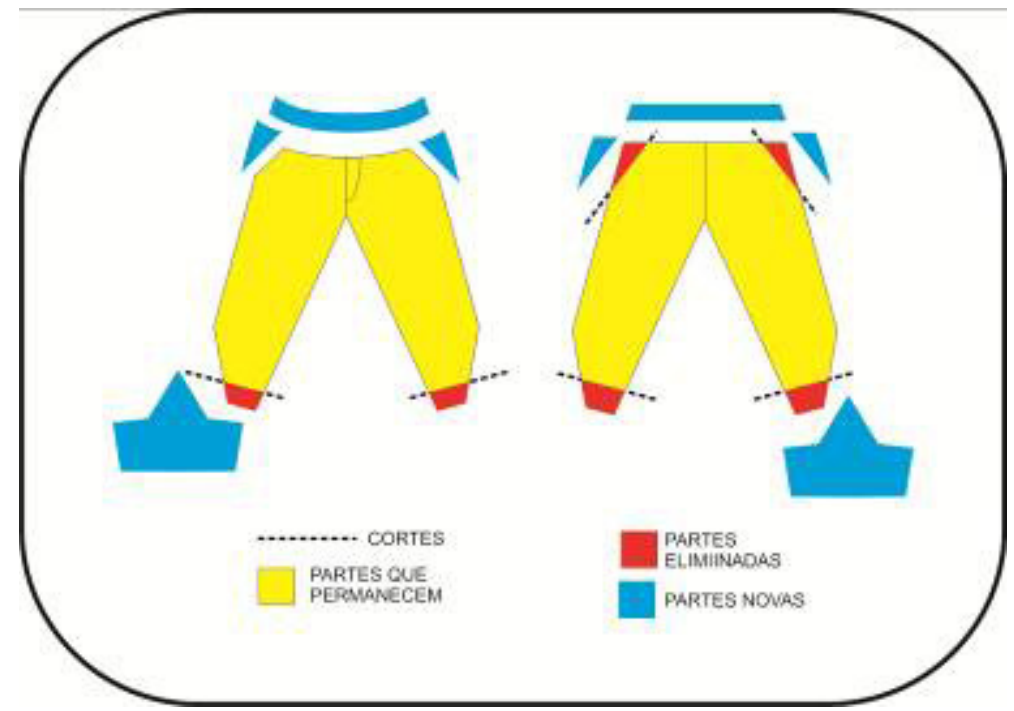

Figura 6 - Criação da nova peça (reconstrução)

Fonte: Elaborado pelos autores 


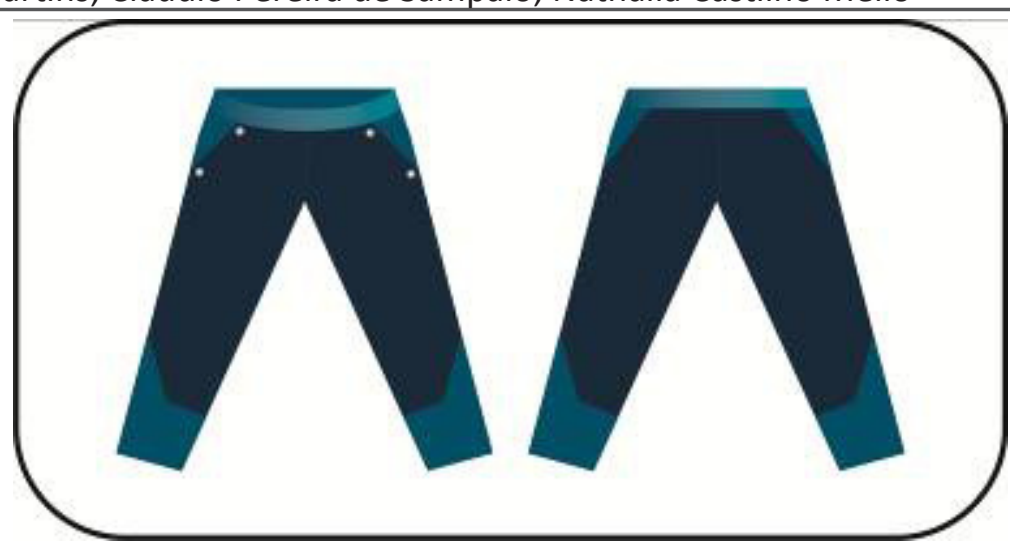

Figura 7 - Nova peça reconstruída

Fonte: Elaborado pelos autores

A partir do mesmo raciocínio, foram geradas 114 alternativas para uma nova coleção, partindo de 37 produtos existentes na coleção outono/inverno 2009 da Lucca Sportwear. A seguir, são apresentados outros exemplos de modificações propostas neste artigo (Figuras 8).
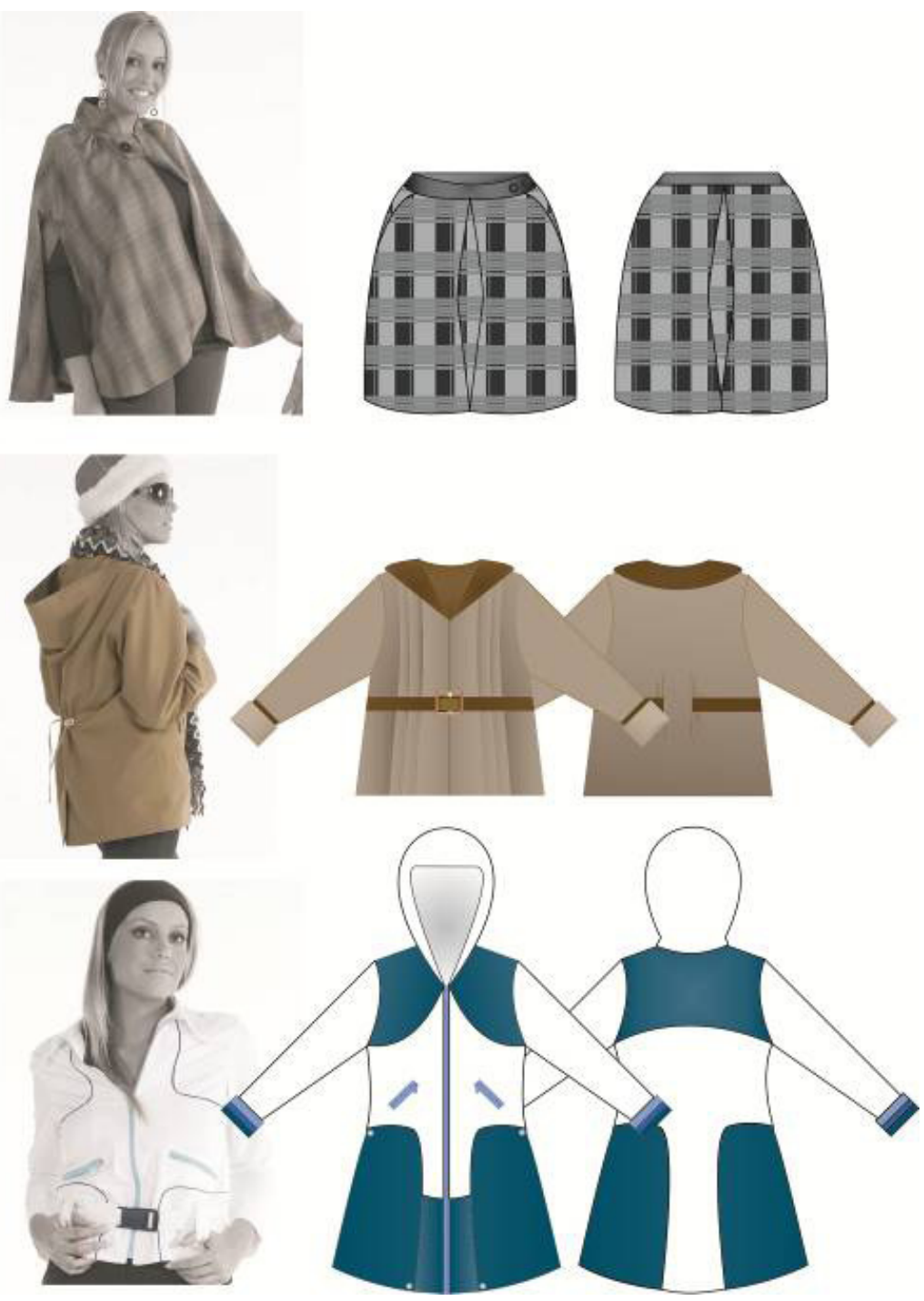

Figura 8 - Aplicação do método em outras peças de vestuário Fonte: Elaborado pelos autores

Projética Revista Científica de Design I Universidade Estadual de Londrina I V.2 I N.1 I Junho 2011 
Moda e Sustentabilidade: proposta de sistema produto-serviço para Setor de Vestuário

Re-modelagem/ produção

Após a seleção das peças com maior viabilidade de produção, o modelista adapta as bases e os moldes pré-existentes para a nova coleção, analisa a usabilidade, e envia o protótipo para a produção. Ressalta-se que essa nova coleção será confeccionada somente em períodos de baixas de produção, após a produção das coleções sazonais.

\section{Marketing}

$\mathrm{Na}$ fase de concepção da nova coleção Eco Lucca, será iniciada uma campanha com flyers e anúncios em rádio e TV, valendo-se das mesmas mídias já utilizadas pela empresa. A campanha de marketing terá como objetivo criar dentro uma nova necessidade para a cliente Lucca: a preocupação com o meio ambiente e o consumo consciente. As clientes serão convidadas ao coquetel de lançamento com desfile e palestra sobre a nova linha e a importância da diminuição dos impactos ambientais em relação aos produtos de moda descartados antes do final de sua vida útil, promovendo o "descarte" de tais produtos dentro da própria empresa.

\section{CONSIDERAÇÕES FINAIS}

No estudo apresentado, foi proposto um novo cenário de sustentabilidade em uma pequena empresa do Setor de Vestuário, aliando interesses econômicos a interesses sócioambientais. Com a nova linha Eco Lucca, busca-se estimular a fidelização das consumidoras, otimizar recursos na construção de uma nova coleção, e manter a produção em atividade em intervalos de baixa produção. Busca-se também reduzir o custo do produto final e diminuir impactos ambientais causados pelo descarte precoce ou incorreto de produtos, além de promover o consumo consciente entre as clientes da empresa, trabalhadores e todos os atores envolvidos no processo e ao mesmo tempo em que procura também atrair novos consumidores sensíveis ao consumo consciente de produtos de moda.

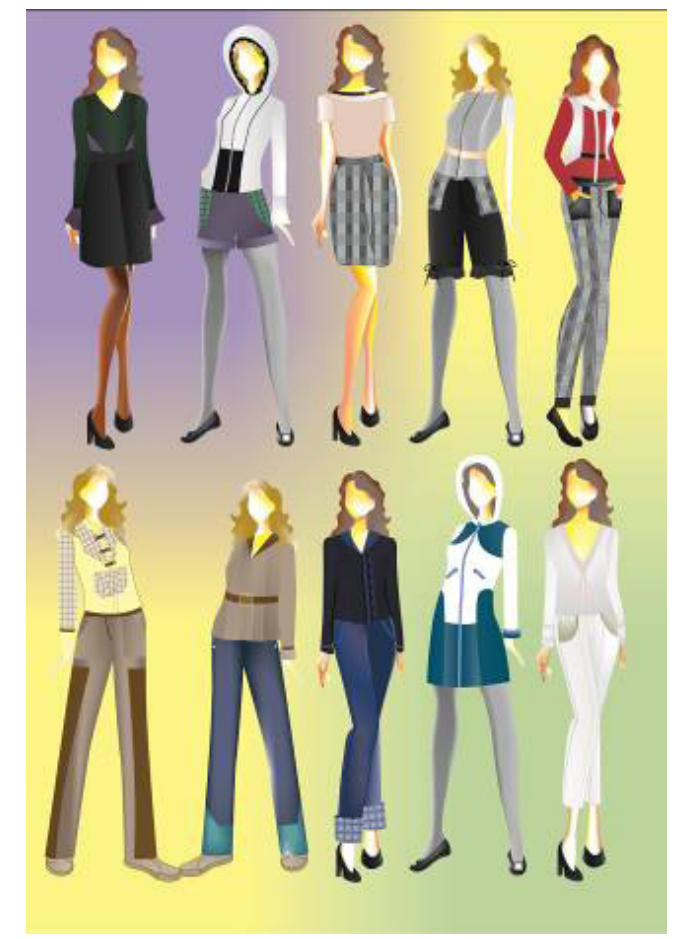

Figura 9 - Proposta final de coleção a partir do sistema Eco Lucca Fonte: Elaborado pelos autores 
Suzana Barreto Martins; Cláudio Pereira de Sampaio; Nathalia Castilho Mello

Como resultado final, obteve-se uma nova coleção com 18 novas peças (Figura 9),

que foram criadas a partir de peças já comercializadas anteriormente. As peças mantêm a fidelidade com a linguagem da marca e as características fundamentais de conforto e praticidade do segmento casual.

Por outro lado, a possibilidade de redução dos impactos ambientais a partir da abordagem de sistemas produto-serviço é algo ainda pouco discutido e aplicado tanto no âmbito acadêmico, a exemplo de cursos de design, como no âmbito empresarial. No caso do ensino de design, a ainda incipiente discussão decorre do fato da sustentabilidade ser tema ainda recente nos currículos, apesar da existência da área do design no Brasil há mais de 50 anos. Em contrapartida, nas escolas européias, por exemplo, as questões sócio-ambientais já são objetos de estudo há algumas décadas. Esta carência de conhecimento tem sido suprida por cursos de mestrado e especializações em design, que apesar de escassos, paulatinamente vêm formando mestres e especialistas em design para a sustentabilidade (DfS).

No caso do design de moda, existe a carência de programas de pós-graduação e grupos de pesquisa com atuação ativa nesta área. Isto, por conseqüência, desemboca em cursos de graduação que ainda não utilizam as questões sócio-ambientais abordadas de forma sistemática, seja devido ao pouco conhecimento dos docentes nessa área, seja pela falta de domínio de metodologias e ferramentas especificas para o DfS. Normalmente, quando se aborda a sustentabilidade nos projetos de graduação, o enfoque ainda é restrito ao produto em si, e não ao sistema como um todo. No entanto, há um movimento crescente de busca por conhecimento atualizado no tema, e cada vez mais, professores e alunos de cursos de design de moda têm buscado inserir a questão da sustentabilidade em seus projetos.

Por outro lado, a falta de conhecimento sobre DfS e PSS nas empresas é também um desafio a ser superado, e tanto estudantes como professores de design podem colaborar de forma decisiva para ampliar o repertório dos empresários. A realização de projetos de graduação com empresas apresenta uma oportunidade única de se inserir nas empresas do Setor de Vestuário e de produtos de moda uma nova forma de abordagem sistêmica em design, aliando aos benefícios econômicos os ganhos sociais e ambientais. Este artigo demonstra, ainda que em caráter experimental, que é possível pensar em novas formas de negócios para as empresas, decorrentes de um novo tipo de pensamento, mais ético, responsável e, por que não dizer, lucrativo.

\section{REFERÊNCIAS}

BRUCE, M.; DALY, L.; TOWERS, N. Lean or agile: a solution for supply chain management in the textiles and clothing industry? International Journal of Operations \& Production Management, Bradford, v. 24, n. 2, p. 151-170, 2004.

BREZET at al. The Design of eco-efficient services. Method, tools and review of the case study based "Designing Eco-efficient Services" project. Delft University of Technology. The Netherlands. 2001. Disponível em < http://www.score-network.org/files//806_1.pdf> Último acesso: 14/01/09.

INSTITUTO PARANAENSE DE DESENVOLVIMENTO ECONÔMICO E SOCIAL - IPARDES. Arranjo produtivo local de confecção do sudoeste: estudo de caso. Curitiba: IPARDES, 2006.

MADSEN, J.; HARTLIN, B.; PERUMALPILLAI, S.; SELBY, S.; AUMÔNIER, S. Mapping of evidence on sustainable development impacts that occur in the life cycles of clothing: a report to the

Projética Revista Científica de Design I Universidade Estadual de Londrina I V.2 I N.1 I Junho 2011 
Moda e Sustentabilidade: proposta de sistema produto-serviço para Setor de Vestuário department for environment, food and rural affairs: environmental resources management. London: ERM, 2007.

MANZINI, E.; VEZZOLI, C. O desenvolvimento de produtos sustentáveis: os requisitos ambientais dos produtos industriais. São Paulo: Edusp, 2002.

MANZINI, E.; VEZZOLI, C. Product-service systems and sustainability: opportunities for sustainable solutions. Milão: INDACO, 2004.

MARTINS, S. B.; CASTRO, M. Moda sustentável: trajetória da criação, produção e comercialização. In: SIMPÓSIO BRASILEIRO EM DESIGN SUSTENTÁVEL, 1., 2007, Curitiba. Anais. Curitiba: SBDS, 2007. Disponível em: <http://www.design.ufpr.br/sbds>. Acesso em: 20 maio 2011.

MARTINS, S. B.; SAMPAIO, C. P. Ecodesign e design sustentável. In: CONGRESSO BRASILEIRO DE PESQUISA EM DESIGN, 7., 2006, Curitiba. Anais... Curitiba: P\&D Design, 2006. CD-ROM.

MARTINS, S. B.; SANTOS, A. Estratégias genéricas para a sustentabilidade no setor do vestuário. In: CONGRESSO BRASILEIRO DE PESQUISA EM DESIGN, 8., 2008, São Paulo. Anais... São Paulo: P\&D Design, 2008. CD-ROM.

MARTINS, S. B. et al. A taxonomy of strategies for achieving environmental sustainability on the clothing sector. In: matics and Design, 2011. p. 23-27. . Design Development \& Research. Cape Town: Faculty of Infor-

MARTINS, S. B.; VASCOUTO, V. Challenges to present fashion consuming society and market possibilities of organic cotton: a sustainable proposition. In: INTERNATIONAL SYMPOSIUM ON SUSTAINABLE DESIGN, 1., 2007, Curitiba. Anais... Curitiba: ISSD, 2007. Disponível em: <http:// www.design.ufpr.br/issd>. Acesso em: 20 maio 2011.

MCDONOUGH, W.; BRAUNGART, M. Cradle to cradle: remaking the way we make things. New York: North, 2002.

VEZZOLI, C. The clothing care function, final report, Sushouse project. Delft: Delft University of Technology, 2000.

VEZZOLI, C.; CESCHIN, F. Sustainable product service systems for personal clothing care. Household and Personal Care, Milano, v. 4, n. 2, p. 24-29, dez. 2008.

VEZZOLI, C.; MANZINI, E. Design for environmental sustainability. London: Springer, 2008.

VIÑOLAS MARLET, J. Diseño têxtil y de indumentária. In: Diseño ecológico: hacia un diseño y una producción en armonía con la naturaleza. Barcelona: Blume, 2005. 